\title{
'No bladder visible on ultrasound scan-has the patient had a cystectomy?' A case of emphysematous cystitis
}

\author{
Holly Ni Raghallaigh, Sophie Rintoul-Hoad, Elizabeth Emsley, Janek Nawrocki
}

Department of Urology,

Brighton and Sussex University Hospitals NHS Trust,

Brighton, UK

\section{Correspondence to}

Dr Holly Ni Raghallaigh, holly. niraghallaigh@doctors.org.uk

Accepted 14 October 2014
CrossMark

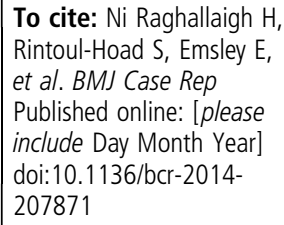

\section{DESCRIPTION}

An 84-year-old man was admitted following an episode of frank haematuria. He had a medical history significant for type-2 diabetes, hypertension and chronic kidney disease (CKD). On arrival, he was febrile at $38^{\circ} \mathrm{C}$ with raised inflammatory markers. An urgent renal tract ultrasound (US) was requested. This commented on an 'absence' of the bladder (figure 1). Owing to worsening renal function, a CT-KUB (kidney, ureters and bladder) was performed. This demonstrated bilateral hydroureteronephrosis, emphysematous cystitis and a distended bladder (figures 2-4). Urethral catheterisation revealed thick, discoloured urine and pneumaturia. The patient was managed with bladder catheterisation, intravenous gentamicin and co-amoxiclav and has clinically recovered.

When present, air in the bladder is most commonly picked up on plain films and CT scanning. Most commonly, this is secondary to recent urinary tract instrumentation (bladder catheterisation, cystoscopy), with colovesical fistulae an important diagnosis to consider.

Less commonly, emphysematous cystitis is the cause. This rare but deadly infection may occur with or without emphysematous pyleonephritis. Classically occurring in older women with diabetes, it carries a significant mortality rate. Diagnosis is usually made radiologically_air being visible

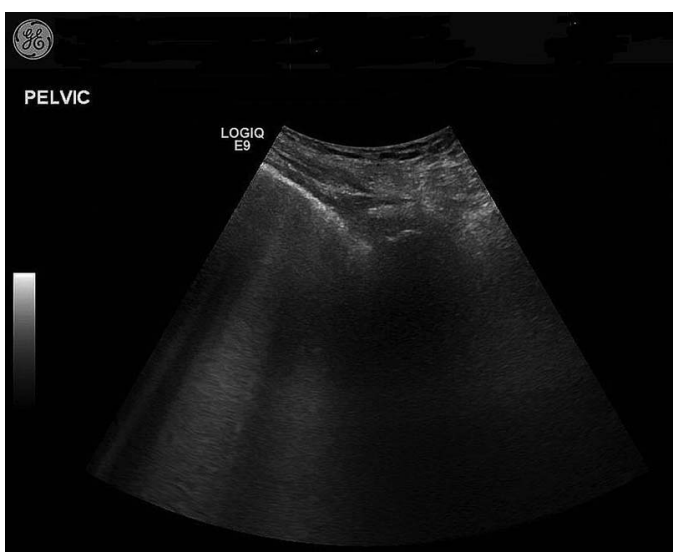

Figure 1 Ultrasound scan of the patients' pelvis. The sonographer was unable to visualise the bladder and thus a cystectomy was queried (however, the patients' distended, gas-filled bladder is clearly visible on CT (figures 2-4)). This can be explained by the fact that ultrasound waves are disrupted by the presence of gas; therefore, assessing the bladder and renal tract using ultrasound in the presence of air (in this case, pathologically due to emphysematous cystitis) is difficult.

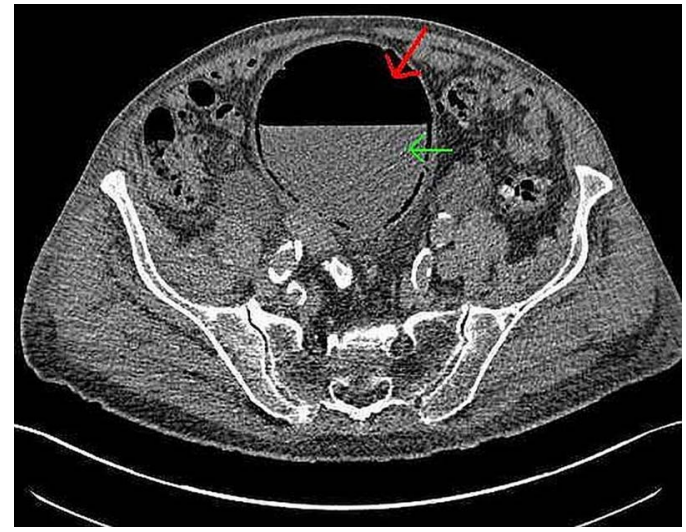

Figure 2 CT-KUB (kidney, ureters and bladder) image in the axial plane. As the patient is lying supine, air from gas-producing organisms rises and is clearly visible (red arrow) over pooled urine (green arrow) in the patient's distended bladder.

within the bladder wall and throughout the bladder itself. Our case report highlights the need for a high index of suspicion for this diagnosis, raised by an 'absent' bladder on US scanning due to large amounts of intravesical air. ${ }^{12}$

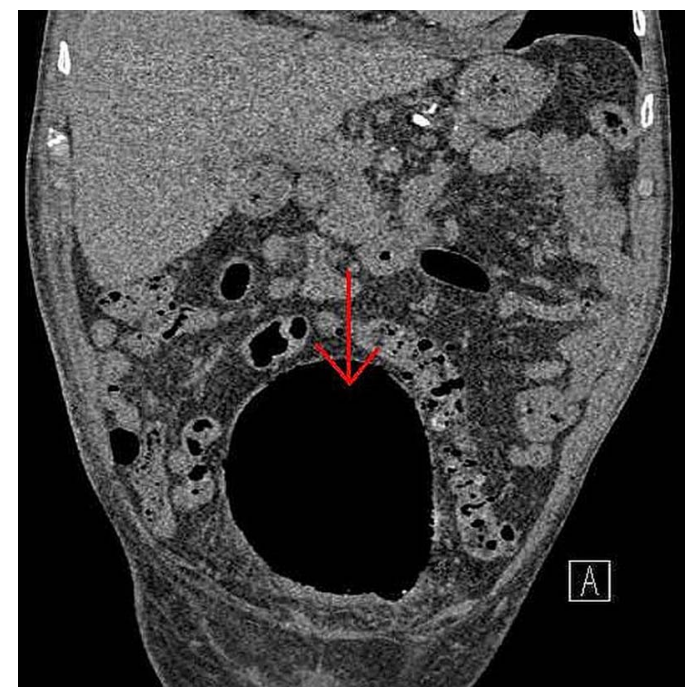

Figure 3 CT-KUB (kidney, ureters and bladder) image in the coronal plane. The patient's bladder is grossly distended, with air clearly visible (red arrow), having risen to the bladder surface as the patient lies supine. In the absence of bladder instrumentation/colonic fistula, the presence of air in this case is due to emphysematous cystitis. 


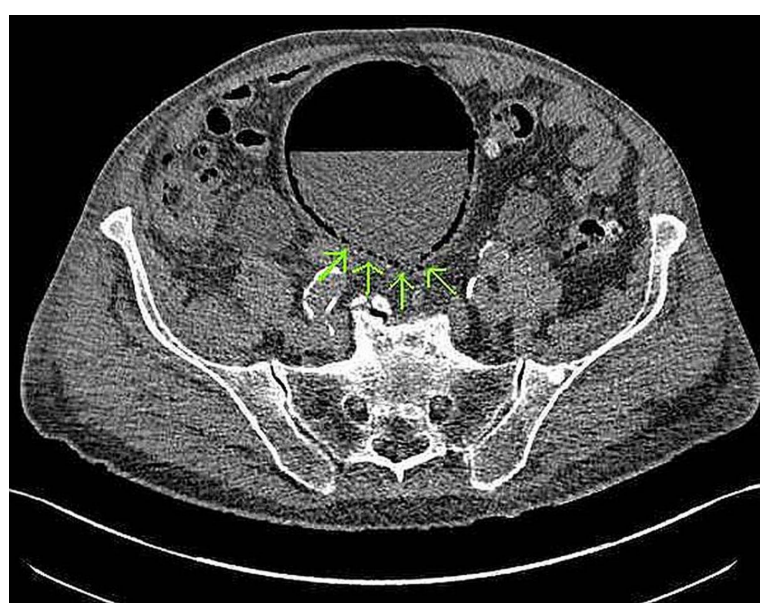

Figure 4 CT-KUB (kidney, ureters and bladder) image in the axial plane. As previously described, the patient is supine. Green arrows point to air visible within the posterior bladder wall due to the presence of gas-forming organisms.

The mainstay of treatment is with catheterisation and intravenous antibiotics, with severe cases occasionally requiring surgical intervention in the form of partial/complete cystectomy. Hyperbaric oxygen therapy has also been described as a successful treatment modality. ${ }^{3}$

\section{Learning points}

- Emphysematous cystitis is an important and often deadly infection, occurring most frequently in older patients with diabetes as a result of Escherichia coli.

- Choice of imaging modality is important, with CT scanning the most sensitive.

- Important differential diagnoses to consider are recent urinary tract instrumentation and colovesical fistulae.

Contributors HNR, SR-H and EE prepared the case report. JN was the overseeing urology consultant.

\section{Competing interests None.}

Patient consent Obtained.

Provenance and peer review Not commissioned; externally peer reviewed.

\section{REFERENCES}

1 Thomas AA, Lane BR, Thomas AZ, et al. Emphysematous cystitis: a review of 135 cases. BJU Int 2007;100:17-20.

2 Quint HJ, Drach GW, Rappaport WD, et al. Emphysematous cystitis: a review of the spectrum of disease. J Urol 1992:147:134-7.

3 McCabe JB, Mc-Ginn Merritt W, Olsson D. Emphysematous cystitis: rapid resolution of symptoms with hyperbaric treatment: a case report. Undersea Hyperb Med 2004;2013:281-4.

Copyright 2014 BMJ Publishing Group. All rights reserved. For permission to reuse any of this content visit http://group.bmj.com/group/rights-licensing/permissions.

BMJ Case Report Fellows may re-use this article for personal use and teaching without any further permission.

Become a Fellow of BMJ Case Reports today and you can:

- Submit as many cases as you like

- Enjoy fast sympathetic peer review and rapid publication of accepted articles

- Access all the published articles

- Re-use any of the published material for personal use and teaching without further permission

For information on Institutional Fellowships contact consortiasales@bmjgroup.com

Visit casereports.bmj.com for more articles like this and to become a Fellow 